\title{
ABSTRACTS
}

\section{I.-GLIOMA RETINAE}

(I) O'Connor, Dennis F. (Worcester, Mass.).-Glioma retınae et atrophia bulbi. Arch. of Ophthal., Vol. XLVI, No. 4, 1917.

(1) O'Connor believes that in his case the glioma was the primary. condition; that the tumour after destroying the retina became almost completely necrotic; and that the necrotic areas became replaced by connective tissue in which the tumour cells again grew; the cell masses thus formed then underwent necrosis and calcification, probably from the lack of sufficient blood supply. $\mathrm{He}$ reviews the hereditary, prenatal, and congenital aspects of these cases, and discusses the available literature. Finally a section is devoted to the differential diagnosis.

R. H. ELLIOT.

(2) Rietz, E.-Glioma of the optic nerve. Hygiea, Vol. LXXX, p. 344, 1918.

(2) E. Rietz remarks that time was when tumours of the optic nerve were believed to originate in its pial sheath, and were described as endothelioma, on the one hand, or as myxoma or fibrosarcoma, on the other. His own patient (Professor Dalén's clinic) was a girl, $3 \frac{1}{2}$ years of age. At the end of December, 1916, her mother noted that the child's right eye protruded somewhat, and later squinted inwards; a month later a watch could be seen a metre off with the left eye covered. Seen on February 17, 1917, the girl showed protrusion of the right eye forwards, inwards and downwards, with unimpaired mobility, loss of vision, enlarged pupil inactive to light but preserving the consensual reaction, iris of normal appearance, refracting media normal. The fundus exhibited a reddened prominent disc with radial striation and obscure margin; the veins were dilated and tortuous. The left eye was normal. Nasal examination showed nothing abnormal in the ethmoid region. Examination with the $\mathrm{X}$-rays showed that the right lamina - papyracea had less sharp angles than the left, and slight thickening in the ethmoidal region. Retrobulbar tumour was diagnosed and the right eye was removed. The optic nerve was club-shaped, hard, and even; no adhesions were present, and no orbital tumour could be felt. The optic nerve was cut as far back as possible, but its end showed evidences of the tumour, so the removal of the growth was incomplete. Five months later no signs of recurrence had occurred. Examination of the optic nerve after removal showed a spindle-shaped intrapial new growth, grey-white in colour, longitudinally striated; the arachnoid and pia were loosened and not 
adherent, and there was no evidence that the tumour had broken through into the intervaginal space. The arachnoid membrane showed definite hyperplasia of the endothelium and connective tissue bundles. The eyeball was oedematous round the papilla, but not invaded by the tumour. The tissue of the tumour itself occupied the dilated interseptal spaces, which were trebled in diameter at the point of maximum enlargement, normal at the lamina cribrosa. The pial septa were thinned out in the tumour and vascluar. The tumour tissue was poor in cells, and showed the specific staining reactions of neuroglia, staining yellow with van Gieson's and red with Mallory's stain, blue by the aniline blue method. It consisted of long tortuous corkscrew fibrils in a network, staining red, while the connective tissue of the pial septa stained blue (staining method not stated). Staining for mucin gave a negative result. Neuroglia cells mainly of two types were seen, and a few nerve fibres and myelin sheaths; no necrosis was observed. Rietz says that two other cases of tumour of the optic nerve in the pathological collection of his clinic showed similar pictures; resembling gliomas of the brain rather than gliomas of the retina in their nature and course.

A. JEX-BLAKe.

\section{(3) Van Duyse, D. (Gand).-Homeotypical glioma of the optic} nerve. (Gliome Homéotypique du Nerf Optique). Arch. d'Ophtal., December, 1922.

(3) In this article van Duyse describes very fully with numerous illustrations, the histological characteristics of a tumour of the optic nerve removed from a boy of 15 , and designates the growth homeotypical glioma. Those interested should read the author's description which would lose much of its value if published in abstract. The author's concluding statement is that homeotypical glioma of the optic nerve has a glioblastic origin and is composed of differentiated neuroglial elements; it is a tumour with benign characteristics and is to be distinguished from heterotypical glioma - glio-sarcoma of some writers-which is essentially malignant.

In the introductory part of his paper van Duyse refers to the question of a non-malignant form of glioma of the retina to which attention has been directed by more than one writer. He says: "In an earlier communication (Arch. d'Ophtal., March, 1922), I have described a homeotypical glioma which arose in the hyperplasic and colobomatous retina of a rudimentary eye with a cystic development behind the upper eyelid. I sought to establish the view of a form of glioma lacking the attribute of pernicious development associated with glioma of the retina, which has become an axiom in our clinics. The tumour was removed from an infant of eight weeks; 18 months later the child was in perfect health. I have since ascertained that 
Sourdille (Arch. d'Ophtal., 1904, p. 87), and Asceunce (Annal. d'Ocul., 1905, p. 133), have expressed similar views in reference to intraocular glioma of benign character. Without adhering to the views on histogenesis of the first-named writer, or the conclusions published by the second, I think that the occurrence of retinal tumours composed of differentiated elements, homeotypical ' adult' as Sourdille puts it, should be accepted in contradistinction to the more frequent, better known tumours composed of undifferentiated heterotypical 'embryonic' elements, which are metastatic and of evil reputation. Apart from the danger due to their situation this type of glioma (homeotypical) would be grouped among the benign tumours clinically. If this proposition were established in reference to the retina it would be equally applicable to the optic nerve."

To explain the difference between the two types of glioma Sourdille suggests that if the proliferation of the neuroglia is of the "adult" form a benign tumour results, while proliferation of the " embryonic" type produces a malignant growth. Histological examination alone will establish the diagnosis and the prognosis. Homeotypical glioma is benign in the sense that glioma of the brain and spinal cord is benign, i.e., a tumour of slow development which only exceptionally involves adjoining structures and is not metastatic.

J. B. LAWFORD.

(4) Gourfein-Welt, Madame L. (Geneva). - A new aetiology of pseudo-glioma: sub- and pre-retinal haemorrhage in the course of whooping cough. (Nouvelle étiologie du pseudogliome: hémorrhagie sous et prérétinienne au cours de la coquelouche.) Rev. Gén. d'Ophtal., February, 1923.

(4) Madame Gourfein-Welt's case is of considerable interest and importance. A girl of five years who had had whooping cough in July and August came to the clinic in November. Except for the condition of the left eye she was in perfect health. The right eye was normal and emmetropic. The left eye showed external strabismus : otherwise its appendages, movements and tension were normal. There was no photophobia, ciliary injection or opacity of the cornea, anterior chamber or lens. The pupil was moderately dilated and did not react to light. Behind the lens was a greyish white mass with several vessels upon it. For safety's sake the case was treated as one of glioma retinae and the eye was excised. On pathological examination the condition was found to be quite otherwise. There were no evidences of glioma. There was a funnel shaped detachment of the retina with, in front of its post-lenticular portion, a mass of organised tissue of haemorrhagic origin, while, between the detached retina and the choroid was a greyish red mass which, from its microscopical composition, represented the remains 
of a large sub-retinal haemorrhage. There was no ascertainable cause of the haemorrhages other than the whooping cough. The author occupies a good deal of space with description of the microscopic appearances, but the above notes will indicate the conditions found. Three drawings accompany the article.

ERNEST THOMSON.

\section{II.-DISLOCATION OF LENS}

(I) Hegner(Jena).-Contribution to the prognosis of dislocation of the lens. (Beitrag zur Prognose der Linsenluxation.) Klin. Monatsbl. f. Augenheilk., Sept.-Oct., 1915.

(1) Hegner has collected 65 cases of dislocation of the lens in which he was able to follow up the after history; 70 per cent. of the patients were over 45 years old, a feature attributable to the changes which occur in the suspensory ligament with advancing years. For purposes of comparison five groups are recognised: subluxation, total dislocation into the vitreous, dislocation into the anterior chamber, congenital and spontaneous dislocation. In connection with subluxation secondary glaucoma is the greatest danger. It occurred in 20 out of 24 of Hegner's cases. The glaucoma may be acute or chronic, miotics and glaucoma operations are useless and extraction is dangerous. In eight extractions four eyes were lost and in only one was good vision obtained. The reason for such bad results is that changes in the vitreous and in the suspensory ligament are always present. In rare cases, however, spontaneous reposition may occur. Partial dislocations only rarely become total; this occurred in only one of 24 cases which were under observation for a considerable time.

Eleven cases of total traumatic dislocation were followed up. Of these only two became glaucomatous; an outcome depending on the fact that in these cases the abnormal stretching of the suspensory ligament is absent. Such lenses sooner or later become opaque and degenerated but do not become completely absorbed. The vitreous is more or less fluid and contains fine opacities, otherwise the eyes show very little reaction and vision, on the average, remains good. in view of these considerations the author suggests reclination in cases of secondary glaucoma due to subluxation. Dislocation into the anterior chamber, whether traumatic or spontaneous is very dangerous. Both inflammatory and mechanical complications occur. In 16 out of 17 cases observed by Hegner there was glaucoma, in the seventeenth an early extraction had been done. Extraction, however, is dangerous here also ; it was done in 13 out 
of the 16 cases, five eyes being lost and useful vision being obtained in only three cases. Lenses in the anterior chamber undergo degenerative changes more rapidly than in other forms of dislocation.

Thirteen cases of congenital and spontaneous dislocation were followed up. They may be divided into two groups; those in which the suspensory ligament is intact and those in which its development is defective. The former group has a relatively good prognosis as neither total luxation nor glaucoma tends to occur. The second group tends to produce complete dislocation, but not glaucoma. To this group belongs a rare condition, familial spontaneous dislocation. Finally, when the lens becomes dislocated in association with an already existing ocular disease such as high myopia or hydrophthalmos the prognosis is bad.

H. M. TRAQUAIR.

(2) Marin (Almeira).- Traumatic subconjunctival dislocation of the lens with intact iris. (Luxation traumatic subconjunctival del cristalino con emigration del mismo e integridad del iris.) Archivos de Oftalmologia Hispano-Americanos, July, 1917.

(2) Marin records the rare result of an ocular injury in a man of 75 years of age. The left globe was ruptured in the upper and outer part, the lens was lying outside, under the conjunctiva, and the iris was uninjured. The vitreous was full of blood. As soon as the wound in the sclera was healed, the dislocated lens was removed through a conjunctival incision. The vitreous haemorrhage cleared up under the use of dionin, allowing a view of the fundus to be obtained. The resulting vision was finger counting at one metre.

R. R. JAMES.

(3) Paine, Howard S. (Glen Falls, N.Y.) - Operation for extraction of lenses fully dislocated into the vitreous. Amer. Jl. of Ophthal., Series 3, Vol. I, No. 3, March, 1918.

(3) A large part of Paine's article is taken up with quotations from distinguished surgeons to the effect that lenses dislocated into the vitreous are inoperable and best left alone. Paine holds that such cases are not always desperate. In operating, the great and vital necessity is to see what one is doing, i.e., to see the lens itself. In order to do this the operation is carried out in artificial light, arrangements being made to illuminate the interior of the eye very thoroughly. The surgeon sits at the patient's head and, after the incision has been made, is able to look down into the depths of the vitreous and see what he is doing. Personally the author wears a 
broad high shade and assists himself with spectacles stronger than those ordinarily worn. He says that Reber recommended "as an operating glass, a sphere with a plus four degree prism, base in." This possibly is a printer's error, for "plus sphere with a four degree prism." In operating Paine passes a Stevens traction hook to the lowest border of the lens, lifting or drawing it into the pupil, then slipping a Smith spatula behind it and sliding it up and out on the spatula by traction on the hook if it holds, or gentle pressure on the outside of the cornea if the hook pulls out." Five successful operations are recorded. It is obvious that the essential point according to Paine is the illumination of the interior of the eye. The exact details of the position and handling of the light do not seem to be given. It is said that the globe should be frosted, with a corkscrew filament, and of about 20 candle power, and a condensing lens is employed. This article is well worth study, but it is the curious mixture of the personal experience and that of others which makes it a little difficult to read.

ERNEST THOMSON.

\section{III.-OCULAR SYPHILIS}

\section{(I) Alter, Francis W.-Palpebral syphilis, a review with case report. Ophthalmology, January, 1916.}

(1) According to Alter, of Toledo, Ohio, a comparison and averaging of the statistics of various observers shows that chancres of the eyelids constitute about three to five per cent. of extragenital chancres. The lesion has some of the characters both of chalazion and hordeolum, but there is a nibbled, punched-out area at the lid margin. The base is indurated, and indolence and chronicity are characteristic. There is enlargement of the preauricular or submaxillary gland. The finding of the spirochaete and a positive Wassermann reaction will help the diagnosis. The lesion seldom develops on the outer skin surface of the lid. It is almost invariably on the actual lid margin, in the canthi, or on the conjunctiva tarsi. It may be accompanied by pannus.

The secondary syphilitic skin eruptions do not affect the lids much, if at all, though mucous patches may occur on the conjunctiva. The most common tertiary lesion is tarsitis. It gives rise to a peculiar form of vascular hypertrophy of the lid, with ptosis.

A. J. Ballantyne. 
(2) Charles, J: W. (St. Louis).-Dental stigmata of syphilis and transillumination in the demonstration of Hutchinson's teeth. Anrer. Jl. of Ophthal., March, 1917.

(2) In the first four pages of this article Charles is mainly concerned with the pathology, from the dental standpoint, of Hutchinson's teeth, and quotes extensively from dental writers. In the last page he describes how, in connection with his work at the Missouri School for the Blind, he had noticed several cases of Hutchinson's teeth in which only one central incisor was notched, and in which he sought evidence of malnutrition in the teeth which had not, in ordinary light, exhibited any abnormality. By placing an electric light behind the incisors it was found in several cases of suspected syphilis not only that the companion tooth of a notched incisor was affected by a disturbance in enamelification of such a kind that the normal enamel could be distinguished from the abnormal, but also that occasionally there was a case, in which no notching had appeared in either tooth, which showed this area of deficient enamel. The reviewer feels that this is an important contribution to our knowledge and that the author's summary of the dental pathology of these cases should be read in the original by thosepossibly most of us - whose knowledge of dental pathology is mainly limited to certain painful experiences.

ERNEST THOMSON.

(3) Marbaix (Tournai). What is the correct attitude to take up where there is mydriasis in an old syphilitic case without any other apparent manifestation? (Quelle attitude prendre en présence d'une mydriase chez un syphilitique ancien sans autre manifestation apparente.) La Clin. Ophtal., November, 1919.

(3) What the author seems to mean is this. Is the mydriasis merely a local sign of a local manifestation of syphilis or is it to be regarded as the warning of the onset of tabes or general paralysis ? In the former case it may be possible to do nothing. In the latter treatment is essential. Assuming that the blood Wassermann is - negative that does not justify abstention from treatment nor the authorization of marriage until the cerebro-spinal fluid has been examined. One's conduct will be guided by the plus or minus result. If the result is positive and indicative of a meningitis then intensive treatment must be undertaken to arrest or retard the onset of general paralysis or tabes. If negative, "abstention (from treatment) is perhaps defensible, the pupillary lesions then indicating a very localised syphilis." Obviously, if the blood Wassermann is positive there is no question as to abstention from treatment.

ERnEST THOMSON. 
(4) Lakaye, Dr. R. (Liège).-Early post-arsenical syphilitic nervous manifestations. (Les manifestations syphilitiques nerveuses précoces postarsenicales.) Arch. méd. belges, July, 1920.

(4) Lakaye draws attention to the numerous cases of early cranial nerve paralysis in syphilis treated by 606 . Such paralyses occur suddenly two or three months after the termination of the first course of treatment and are sometimes preceded by general symptoms such as headache and prostration. Lumbar puncture at this time gives evidence of abundant leucocytosis with albuminosis, indicating a cerebral and spinal meningitis, chiefly basilar. Such meningitis in the secondary period was known to be of frequent occurrence, but did not, in the absence of arsenical treatment, generally give rise to any serious symptoms. Lakaye considers that this treatment renders the central nervous system less resistant to an affection it is otherwise capable of resisting. He quotes illustrative cases in support of his contention that it is at the outset of secondary symptoms that these accidents occur and in the presence of a negative blood Wassermann reaction. He points out that the best way of avoiding these accidents is to combine arsenical treatment with mercurial injections either simultaneously or alternately, and prefers the more soluble preparations such as the cyanide, biniodide or benzoate.

In treating the paralyses he continues the arsenical treatment in small doses very slowly increased, but not beyond $60 \mathrm{ctgs}$. At the same time he administers every week an intramuscular injection of 10 ctgs. of salicylate of mercury or of calomel. The result has always been successful except in some cases of facial paralysis in which slight atrophy of the muscles has remained.

The paper is not written for ophthalmic surgeons, but so many of the cases recorded affected ocular nerves as to render it of some interest to our readers.

E.E.H.

(5) Darier, A. (Paris).-The diagnostic importance of heredospecific teeth. (Importance diagnostique des dents hérédospécifiques.) La Clin. Ophtal., September, 1922.

(5) Darier has before alluded to the importance of the first permanent molar as a tooth which, as well as the incisors, may be affected in hereditary syphilis. He returns in this article to the subject which will be found discussed in full in his "Traité complet de Thérapeutique oculaire," published in 1921, and reproduces the diagram which will be found on page 25 of that work. The enamel or gum of the first permanent molar ossifies one month before birth, those of the median incisors in the first month of life, 
and those of the lateral incisors and canines in the fourth and fifth months of life. The importance of these facts is obvious when one is considering a case of hereditary syphilis, since, according to whether one or other or all three of these dental groups are affected one can form a judgment as to the era of incidence of the disease. The drawing shows the usual notch in the incisors, the single bare peg of dentine in the canines and the four bare pegs of dentine in the first permanent molar.

ERNEST THOMSON.

(6) Gourfein. D. (Geneva).-The efficacy of bismuth salts in the treatment of ocular affections of syphilitic origin. (L'efficacité des sels de bismuth dans le traitement des affections oculaires d'origine syphilitique.). Rev. Gén. d'Ophtal., April, 1923.

(6) Gourfein continues his observations on intra-muscular injections of tartro-bismuthate of potassium and sodium, the first notes on which were published by him in the Revue Génerale d'Ophtalmologie for January, 1922, and were abstracted in this Journal for June, 1923, q.v. Gourfein has now treated 33 cases of syphilitic eye disease and reports nine of them in detail. Of these nine, three were cases of iridocyclitis, four of paralysis of muscles, and two of choroido-retinitis. The results have been very satisfactory, and the author concludes that bismuth is a first class "treponemicide," though he admits that its effect upon the serum-reaction is less rapid than upon the symptoms of the disease. Reference to the abstract of his previous article above referred to will show that at that time Gourfein said "The future only can show whether this treatment realizes the much-wished-for "therapia sterilans magna." Apparently it does not, at any rate in some cases. The conclusion come to is that treatment by the salts of bismuth presents great advantages. It is active, and rapidly cures syphilitic ocular " accidents." It frequently sterilizes the organism. It is well tolerated both by adults and children. It does not expose the patient to grave optic nerve complications nor to other nervous complications like serous apoplexy. In short it does not present the possibility of danger or inconvenience as does arsenobenzol medication. Both these articles will repay perusal.

ERNEST THOMSON. 


\section{IV.-TRAUMATIC AFFECTIONS OF RETINA}

(1) Stähli (Zürich).-Contribution to our knowledge of traumatic angiopathy of the retina. (Zur Kenntnis der Angiopathia retinae traumatica.) Klin. Monatsbl. f. Augenheilk., Sept.-Oct, 1915.

(1) Traumatic retinal angiopathy was described by Purtscher in 1910. Following severe injury to the skull white spots and haemorrhages occur in one or both eyes in the area of the nerve entrance and macula.

Stähli's patient fell off a vehicle injuring the right occipital region and suffering many other minor injuries. Beyond some blood in the conjunctivae there was no other sign of cranial injury. A good recovery was made in every way but the vision of the right eye was reduced and that of the left almost destroyed. A month after the accident both fundi showed numerous and extensive white patches and small haemorrhages. The lesions were more pronounced in the left eye. In other respects the eyes were normal. Some recovery of vision took place and the fundus changes diminished. A year later the fundus changes had practically disappeared but both optic nerves were pale especially on the temporal sides. Useful vision was absent in the left eye owing to a large central scotoma but the right eye could read $5 / 6$ with difficulty. Stähli regards this condition as closely related both in causation and in nature to Berlin's opacity in commotio retinae.

H. M. TRaQuair.

(2) Francisco, M. Fernandez.-Traumatic retinal detachment in both eyes. (Desprendimiento de la Retina en ambos ojos de origen traumatico.) Cronica Medico Quirurgica de la Habana, December, 1918.

(2) The author records the case of a man who received a severe injury to the head and one arm in a riding accident. The patient was badly concussed and was unconscious for ten days; on. regaining consciousness he complained of a defect of sight in each $\tilde{D}^{-}$ eye. Ophthalmoscopic examination revealed in each a transparent $\omega$ detachment of the retina, extending up to the disc and involving the macula.

The treatment adopted was purely medical, absolute rest in bed, $\stackrel{\Phi}{\Phi}$ nux vomica internally, sweating by means of pilocarpin injections, 0 and, locally, dionin and heat. After four months treatment the 0 man had completely recovered.

R. R. James. 
(3) Lacroix.-Traumatic detachment of a retinal vein. (Décollement traumatique d'une veine rétinienne.) Arch. d'Ophtal., Jan.-Feb., 1919.

(3) The patient, a soldier, was struck by a splinter of wood inflicting a non-penetrating wound of the left upper lid close to the inner canthus. When admitted two days later vision was handmovement at $10 \mathrm{~cm}$. There was no external lesion of the eyeball. Dust-like opacity of the vitreous obscured the fundus. Six days later the fundus was visible and choroido-retinal ruptures were discovered close to the O.D. After another five days' interval the vitreous was almost clear and a large choroido-retinal rupture in the macular region was discovered. Starting from near the upper border of the disc a long narrow rupture passed obliquely across the fundus and extended towards the ora serrata.

The inferior temporal vein, after running its usual course for a short distance, suddenly left the retinal level and protruded anteriorly. The displacement of the vessel was considerable; it was free in the vitreous, and was obviously attached at the periphery, as its contour and calibre were normal and its blood stream uninterrupted. The subjacent retina was not detached and showed no breach of continuity, though the colour of the fundus at this part was paler than elsewhere. No modification of these appearances occurred during the month following the injury. The man was then evacuated.

J. B. LAWFORD.

(4) Frenkel, Henri (Toulouse).-A new case of folding of the retina in circles due to contusion of the posterior segment. (Un nouveau cas de plissement en cercles de la rétine par contusion du segment postérieure.) La Rev. Gén. d'Ophtal., Janvier, 1920.

(4) We welcome the reappearance of this Journal, the publication of which was in abeyance during the war.

Frenkel in 1917 published a case of multiple detachments of. the retina in circles which was then considered unique, but the same author has come across a second case almost exactly the same, and due, in the author's opinion, to the same cause, namely, contusion due to windage of a shell. The case is described in detail and a plate shows the detachments very well. The first case has been seen again and was found to present exactly the same lesions as when first examined in 1916. In addition the disc was found to be cupped and atrophic and the tension plus 1 . The present case was first examined in 1918, though the accident of exposure to shell windage occurred as far back as 1915. The author conciudes that this form of retinal detachment has a tendency to remain stationary. He does not feel disposed to risk a hypothesis as to the chronic glaucomatous condition which has supervened in the first case.

ERnest Thomson. 